\title{
Estudo de Caso no Curso de Ciência da Computação/UFPEL: \\ Aulas Remotas Utilizando Streaming de Vídeo e Chat como Ferramenta de Comunicação Interativa
}

Kelly Hannel*,

Verônica Burmann da Silva**,

Raymundo Ferreira Filho**,

Ricardo Azambuja Silveira

Resumo. Devido ao fato do constante avanço tecnológico na área de redes e a conseqüente diminuição dos custos de implementação dos sistemas de videoconferência, eles tem sido bastante difundidos principalmente os baseados na Web. É criado um ambiente numa aula de videoconferência, em que tanto professores como alunos, separados geograficamente, podem se comunicar por imagem e som ao mesmo tempo. Por suas próprias semelhanças e diferenças com o ensino "face-a-face", este modelo de ensino a distância evidencia defeitos e qualidades da educação presencial praticada na maioria de nossas universidades. $O$ objetivo do presente artigo é, dentro deste contexto, descrever uma experiência de aula remota no curso de Ciência da Computação da UFPel, e também, evidenciar a impressão dos alunos quanto à experiência.

Palavras - Chave: videoconferência, ensino à distância, aula remota.

Abstract. Due to the fact of the constant technological progress in the area of nets and the consequent decrease of the costs of implementation of the videoconference systems, they have been quite spread mainly based them on the Web. An atmosphere is created in a videoconference class, in that teachers and students, separated geographically, they can communicate for image and sound at the same time. For their own similarities and differences with the teaching "face-to-face", this teaching model the distance evidences defects and qualities of presencial education practiced in most of our universities. The objective of the present article is, inside of this context, to describe an experience of remote class in the course of Computer Science of UFPel, and also, to evidence the students'impression as for the experience.

Keywords: videoconferencing, teaching at the distance, distance learning.

\footnotetext{
* 9o Semestre de Bacharelado em Ciência da Computação Universidade Federal de Pelotas, e-mail: hkelly@ufpel.edu.br.

** 9o Semestre de Bacharelado em Ciência da Computação Universidade Federal de Pelotas, e-mail: vebs@ufpel.edu.br.

*** Mestre, Universidade Federal do Rio Grande do Sul, e-mail: paka@ufrgs.br.

**** Doutor, Universidade Federal de Pelotas, e-mail: rsilv@ufpel.edu.br.
}

V. $3 \mathrm{~N}^{\circ} 1$, Maio, 2005 


\section{Introdução}

No ambiente global em que estamos inseridos, as comunicações "face-a-face" têm sido substituídas pela comunicação virtual através do uso de ferramentas como e-mail, programas de mensagens instantâneas ou comunicação por voz na Web. Além destas ferramentas, cita-se o uso de meios já consagrados como o telefone, o fax ou o modem para satisfazer as necessidades de comunicação corporativas. A Web é uma tecnologia que agrega vários meios de comunicação, como telefonia, TV e rádio. Além destas características, a Web traz a possibilidade de uso da videoconferência através de redes de computadores, oferecendo uma solução acessível a esta necessidade de comunicação, com sistemas que permitem transmitir e receber informações visuais e sonoras entre pessoas em lugares distantes, otimizando o tempo e minimizando os efeitos da distância, uma vez que pessoas podem se reunir virtualmente, ou seja, sem a necessidade de estarem presentes fisicamente no mesmo local, evitando assim os gastos e perda de tempo que ocorrem para as pessoas se locomoverem de um lugar para outro; tudo isto com custos cada vez mais baixos e com melhor qualidade de sinal.

De acordo com Tarouco, Liane M. R.; et all (2003) estudos realizados por grupos de pesquisa demonstraram que a aplicação de diferentes tipos de mídias, como compartilhamento interativo de documentos, a apresentação de gráficos e o uso de áudio e vídeo em tempo real, fizeram com que assuntos antes cansativos, nas salas de aula tradicionais, se tornassem atraentes aos alunos, aumentando a motivação destes no processo de aprendizagem.

A função deste artigo é ilustrar a transmissão da aula a distância ministrada para alunos do curso de Ciência da Computação da UFPEL. Sendo que a descrição do modelo utilizado nesta aula encontra-se descrito no capítulo 2. Para entender o modelo que será descrito, é importante sabermos alguns conceitos que são descritos abaixo.

Streaming é uma tecnologia de compressão de dados que permite transmitir conteúdo multimídia sobre uma rede de dados local (LAN) ou de longa distância (WAN) em fluxos contínuos. Na prática, isso significa que o usuário pode ter acesso ao conteúdo desejado conforme o mesmo vai sendo baixado no local de destino, isto é, não é preciso esperar o processo de download terminar para assistir a um programa de TV, um show, uma palestra ou ouvir uma música pela Internet. Mas é preciso ter um programa chamado "player" instalado no PC, notebook, handheld ou aparelho celular, para visualizar arquivos de streaming. Grandes fabricantes como Microsoft, Real Networks e Apple oferecem seus players para download gratuito em seus sites na Web.

Além disso, streaming é um método utilizado para transmissões de seminários, apresentações comerciais, aulas de ensino a distância, publicações e discussões de pesquisas e experimentos, por exemplo. Tipicamente, as transmissões possuem um nodo que é o principal transmissor, e os outros nodos participam em menor escala na transmissão, fazendo, por exemplo, perguntas em uma palestra (que, neste caso acontecem por meio de outras ferramentas como chat, e-mail, enquetes, etc). Veja a figura abaixo: 


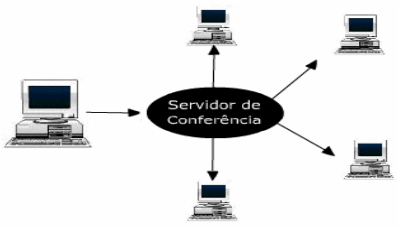

Fig. 1- Broadcast

$\mathrm{Na}$ aula em questão, foi usada a tecnologia de streaming de vídeo, sendo que os softwares utilizados foram o Real Producer (da Real Systems), o Messenger (software da Microsoft com distribuição gratuita), e o Real Player (software de Real Systems com distribuição gratuita). Como complemento, os slides referidos durante a apresentação foram disponibilizados aos alunos antes do início da aula, através da URL http://iate.ufrgs.br//ms/.

\section{Descrição do modelo}

Por enquanto foi realizada apenas uma aula utilizando o modelo detalhado a seguir, sendo que esta poderá servir como base para as futuras. O tema foco da aula foi Ontologias e ocorreu em novembro de 2004. Essa aula foi dada aos alunos da cadeira de Inteligência Artificial I do curso de Ciência da Computação UFPEL pelo Prof. Msc. Raymundo Ferreira Filho, o qual a ministrou em seu laboratório no CINTED/UFRGS. Nesta aula, foi usado o sistema de streaming da empresa RealNetworks composto pelo servidor de mídia Helix Server e do software Helix Producer, no lado servidor, e pelo Real Player, no lado cliente. Veja a figura abaixo, que é um esquema da aula dada, e foi modificada a partir de Sally Thornhill, et all (2002).

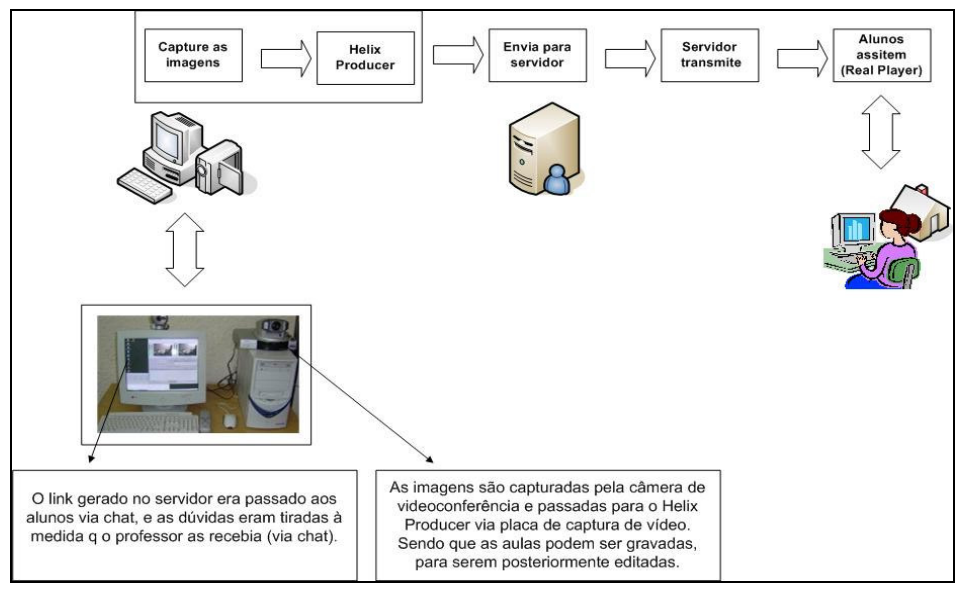

Fig. 2- Processo de desenvolvimento de uma aula usando streaming.

A figura acima traz a idéia de Sally Thornhill, et all (2002), os quais afirmaram que pedagogicamente a aula por streaming é muito interessante, pois agrega colaboração, contextualização e comunicação. E estes três fatores agregados foram utilizados na aula em questão.

$\mathrm{Na}$ sala de onde foi transmitida a aula, foi utilizado um computador com uma câmera própria para videoconferência, ligada ao computador via placa de captura de vídeo, o sinal 
gerado durante a aula era enviado para o servidor de streaming da UFRGS pelo o software Real Producer (ver Fig. 3). O link gerado no servidor foi enviado via chat aos alunos, e também podia ser obtido na plataforma de gestão de cursos Claroline, de onde os alunos obtiveram os slides.

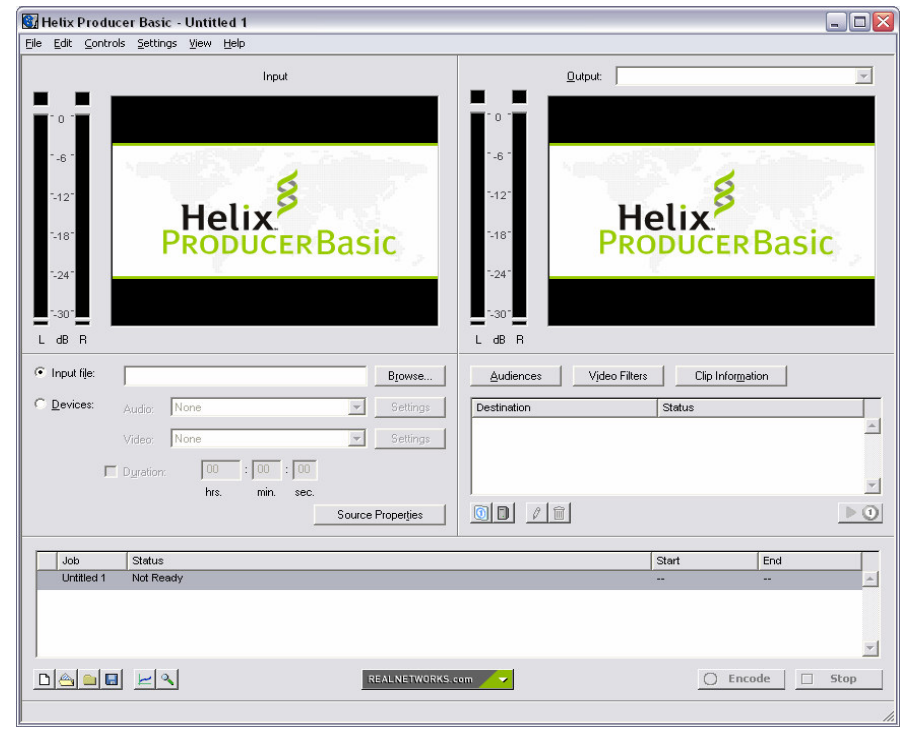

Fig. 3- Helix Producer Basic

A câmera captura as imagens e transmite ao Helix Producer. Na figura acima, o que está sendo capturado aparece abaixo de "input", e abaixo de "output" aparecem as imagens que estão sendo enviadas ao servidor. Abaixo da tela output, aparece o destino para o qual o arquivo está sendo enviado, no caso o servidor da UFRGS. No Helix Producer, é possível configurar a audiência, isto é, se vai ser transmitido a 56, 100, 150, $256 \mathrm{KBps}$, etc, como mostra a próxima figura. É importante configurar a audiência numa velocidade intermediária, para tanto quem tem conexão de alta velocidade quanto os que têm internet discada, possam assistir ao vídeo sem muita perda de qualidade.

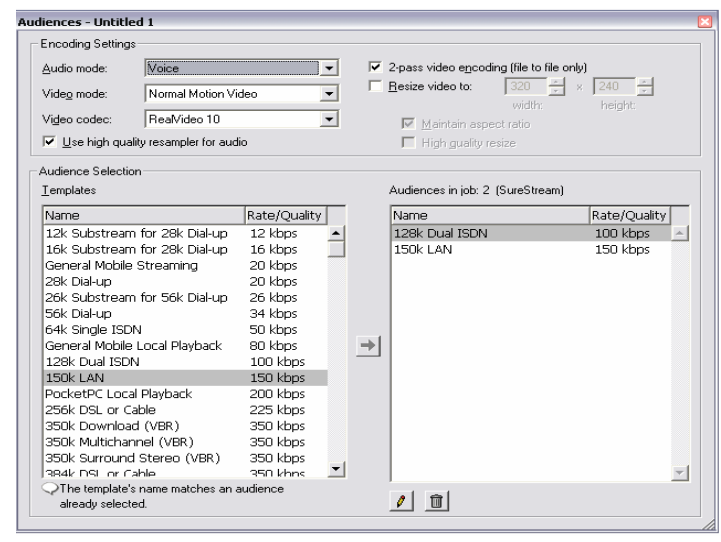

Fig. 4- Audiências do Helix Producer 
Os alunos se conectavam ao servidor e passavam a assistir a aula no Real Player, veja a Fig. 5, onde temos a captura de alguns momentos da aula. Como eles já haviam recebido os slides, era possível acompanhar a aula. As dúvidas que iam surgindo, eram passadas ao professor via chat, no caso, o chat usado foi o Messenger.

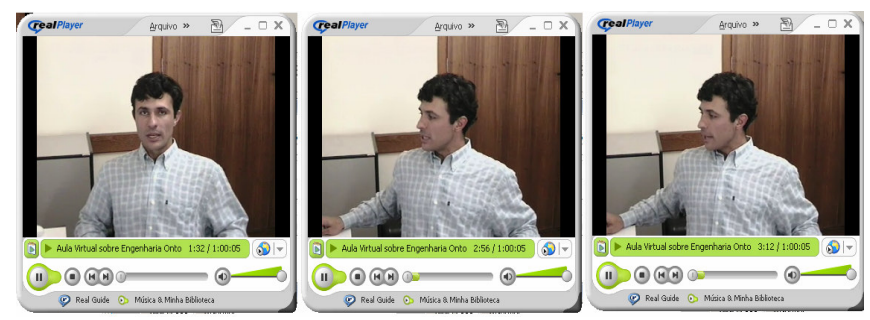

Fig. 5-. Telas mostrando momentos diversos da aula transmitida por streaming

À medida que os alunos assistiam a aula, as dúvidas que surgiam eram passadas ao professor via chat, este recebia as dúvidas no computador e as respondia via vídeo. Isto é, o professor só utiliza o chat para receber as questões, mas as respostas são dadas oralmente no decorrer da aula. O motivo da interação dos alunos com o professor ser feita via chat foi o tipo de transmissão que não possibilitava a utilização de áudio e vídeo pelo lado cliente.

\section{Impressão dos alunos}

Ao final da aula, foi solicitado aos alunos que dessem sua opinião sobre a mesma. Foram dadas opiniões diversas, as quais variaram principalmente com tipo de conexão usada pelo aluno. Um aluno que assistiu a aula via internet ADSL 256KBps disse: "acho que o aproveitamento é até melhor do que a aula presencial, pois não tem as conversas paralelas de alguns colegas...". Já um aluno que assistiu a aula via internet discada 56KBps disse o seguinte: "a aula foi boa, mas me distraí muito, porque o som chegava antes da imagem, e aí ficava prestando atenção nos movimentos do professor....". E a maioria dos alunos, que assistiram à aula na própria universidade, achou a aula bastante proveitosa, e que apesar de ser a primeira vez que participaram de uma aula a distância disseram sentir-se bastante à vontade.

Através do retorno dos alunos, pode-se concluir que a experiência foi válida, entretanto, observa-se que o critério de aprendizagem é bastante subjetivo, e depende muito do ambiente onde $\mathrm{o}$ aluno se encontra no momento, como pôde ser visto pelas diferenças de opiniões.

\subsection{Pontos Positivos}

Os pontos positivos mais ressaltados foram: poder assistir a aula em casa e economizar com passagem. Além desses motivos foram citados outros; como poder ter aula com professores de outras universidades, os quais não teriam disponibilidade de tempo para se deslocarem a Pelotas para dar uma aula presencial. 


\subsection{Pontos Negativos}

A principal reclamação dos alunos foi quanto aos atrasos da imagem, que deixaram a aula cansativa. Como a voz chegava antes das imagens eles acabavam prestando atenção nos movimentos que demoravam a chegar e desviavam a atenção da aula. Além disso, alguns citaram a dificuldade de concentração.

\section{Conclusões}

O modelo adotado foi considerado válido devido ao exame dos relatórios obtidos após esta aula. Foram feitos muitos testes antes da realização dessa aula, buscando proporcionar uma aula de boa qualidade ao aluno, e não somente que eles fossem fazer parte de uma experiência. Procurou-se tornar a aula agradável e interativa, sendo que os alunos podiam interromper o professor, a qualquer momento, para fazer perguntas e colocações. Além disso, procurou-se colocar algumas vantagens que não existem em aulas presenciais, como a gravação simultânea da transmissão, permitindo ao aluno rever a aula, ou assistir em outro horário.

Foram constatadas algumas dificuldades quanto ao modelo da aula, como por exemplo:

- No modelo de aula remota utilizada, o material deve estar pronto, organizado e disponibilizado com antecedência, e esse material deve ter certa seqüência, permitindo ao professor indicar ao aluno exatamente a página, número de slide, etc, ao qual ele está se referindo, mantendo assim o sincronismo entre a transmissão de vídeo e o material de apoio;

- O professor deve se acostumar a falar para uma câmera e não para um grupo de alunos;

- O professor tem que evitar gesticular demais e fazer movimentos bruscos, porque como a imagem chega atrasada em relação ao som, se torna desagradável ao aluno;

- A aula síncrona é bem mais cansativa para o professor do que uma aula tradicional, pois requer domínio da tecnologia envolvida, preparação cuidadosa do material, preocupação constante se tudo vai dar certo, técnico de apoio para apoiar em alguma atividade tecnológica, preparação dos alunos, e assim por diante.

A experiência demonstrou pontos positivos e negativos da experiência, por parte dos alunos, sendo que os principais pontos positivos são: poder assistir à aula em casa e economizar com passagem e tempo. Já os principais pontos negativos são a dificuldade de concentração e os atrasos na imagem. Mesmo com estes pontos negativos, considera-se que os pontos positivos os superam, provando a teoria de que este modelo de aula é válido. Entretanto, considera-se que o melhor aproveitamento aos alunos seja através da divisão da disciplina em aulas remotas e presenciais, buscando o melhor dos dois mundos em sintonia com a característica de cada disciplina, onde se possa vir a aplicar este modelo.

É importante salientar a necessidade de que a relação pedagógica seja elaborada com base metodológica e planejamento para cada disciplina. Aos professores caberá o maior esforço reconstrutivo neste processo, pois será necessário agrupar todas as teorias modernas 
$-\int$ CINTED-UFRGS Novas Tecnologias na Educação de aprendizagem para que os objetivos sejam alcançados, já que este ainda é um modelo novo de ensino e aprendizagem. 


\section{Referências}

RealNetworks, Inc (2002) "Helix Universal Server Administration Guide", http://service.real.com/help/library/guides/helixuniversalserver/realsrvr.htm.

RealNetworks, Inc (2002) "Real System Production Guide",

http://service.real.com/help/library/guides/production8/realpgd.htm.

InfoMed, Red Telemática de Salud en Cuba (2000) "La Videoconferencia en la Educación a Distancia",

http://www.sld.cu/libros/distancia/cap3.html.

Tarouco, Liane M. R.; Granville, Lisandro Z.; Fabre, Marie-Christine J. M.; Tamusiunas, Fabrício R. (2003)

"Videoconferência", Rede Nacional de Pesquisas (RNP) - Grupo de Trabalho Aplicações Educacionais em Rede.

Roesler, Valter; Ceron, João Marcelo; Andrade, Maiko (2003) "Aulas remotas online utilizando transmissão de vídeo: um estudo de caso na Informática da Unisinos", http://prav.unisinos.br/artigos/sbie2003.pdf.

"Claroline: Open source e-learning", http://www.claroline.net/.

Sally Thornhill, Mireia Acensio, Clive Young (2002) "Video Streaming: A Guide for Educational Development", http://www.clicandgovideo.ac.uk. 